\title{
Perfil do profissional de informação tecnológica e empresarial
}

\section{Katia Maria Lemos Montalli}

\section{Resumo}

O presente artigo investiga, junto à Rede de Núcleos de Informação Tecnológica do PADCT, junto ao Sistema de Informação do Sebrae e ao da CNI-CAMPl's, o sexo, a escolaridade e a preferência de formatos de oferta de cursos de especialização.

Do universo total, $69,2 \%$ de respostas foram tabuladas. Existe uma pequena superioridade masculina quanto ao número de profissionais de informação tecnológica empresarial, sendo que mais da metade deles tem graduação completa. É bastante reduzido o número de profissionais com mestrado e doutoramento. Administração e economia formam as áreas de origem mais freqüentes desses profissionais. O formato preferido para cursos de especialização é de um mês, intervalo de três, outro mês, seqüencialmente até o final da carga horária. Para cursos de curta duração, a preferência é que sejam oferecidos em período integral. Conclui-se também que existe uma demanda potencial para programas de mestrado e doutorado. Sugere-se a criação de, pelo menos, um curso de especialização em informação tecnológica empresarial por região, além de maiores investimentos em capacitação de recursos humanos. Sugere-se ainda a realização de pesquisas sobre o impacto dos egressos dos cursos de especialização oferecidos pela UFSC e UFMG e que as investigações sejam realizadas por sistemas de informação.

\section{Palavras-chave}

Capacitação de profissionais da informação; Globalização da Informação; Informação industrial/empresarial; Domínio do sexo masculino na informação tecnológica;

Profissionais de informação do Sebrae.

\section{INTRODUÇÃO}

A prestação de serviços de informação às empresas ganha outras dimensões a partir do novo paradigma que ora se impõe. Com a competitividade e a globalização, a informação torna-se imprescindível para a sobrevivência das empresas. Estas a utilizam por intermédio de sistemas públicos ou por meio de empresas comerciais prestadoras de serviços de informação, além, naturalmente, da informação disponibilizada dentro da própria empresa.

Conseqüentemente, a adequada capacitação de profissionais de informação para atender a empresas/indústrias merece ser contemplada de forma mais contundente nas políticas industriais, de ciência e tecnologia e de informação.

As empresas de micro e pequeno portes necessitam das redes públicas de informação para melhorar suas performances; por outro lado, as médias e grandes empresas estimulam a criação de empresas privadas de informação, para atender a suas demandas; surgem, portanto, novas oportunidades de negócios e de empregos para os profissionais de informação tecnológica/ empresarial.

As médias e grandes empresas precisam ter sua informação interna organizada e disponível, ou seja, precisam criar sistemas on-line internos que organizem a informação produzida pelos diferentes departamentos da empresa - in-house information system. Estes sistemas geralmente são compostos pelo Sistema de Informação Gerencial, Sistema de Suporte à Decisão, Sistema de Informação Executiva, Sistemas Aplicativos de Negócios e, quando for o caso, Sistema de Informação para Pesquisa e Desenvolvimento.
Entretanto, além da informação interna, gerada e disseminada pelos departamentos da empresa, esta necessita ainda de bons profissionais de informação capazes de selecionar a enorme gama de variados tipos externos de informação, dispostos em diferentes formatos/fontes de informação, impressos, bases de dados, sistemas on-line, instituições, contatos pessoais, experts e outros.

Portanto, com a globalização, podemos afirmar que se ampliam as oportunidades de negócios na área de prestação de serviços de informação para empresas/indústrias, bem como ampliam-se as oportunidades de negócios para as escolas que capacitam este tipo de profissional. No novo paradigma, a informação tecnológica e para negócios ganha nova dimensão. Concomitantemente, porém, aumenta a responsabilidade das escolas que irão capacitar o profissional que deverá atender a essa demanda por informação.

A questão que se apresenta é a definição do perfil do profissional que deverá executar essa função. Se, por um lado, é grande o manancial de fontes de informação disponíveis on-line, facilmente acessíveis às empresas, por outro lado, faz-se necessário selecioná-las e recuperá-las, precisa e rapidamente, de forma menos custosa. Outro aspecto a ser considerado são as necessidades locais/regionais de informação não cobertas pelas bases de dados internacionais. Que tipo de formação básica e capacitação complementar o profissional de informação deverá ter? Assim como a globalização amplia as oportunidades na área, abre novas perspectivas para o empresário de informação oriundo do exterior instalar-se no país. Acirra-se a competição! 
Alguns autores contribuem para a discussão da temática ora proposta: enquanto Faulkner (1994) e Gibbons (1994) abordam o tema importância do conhecimento no processo de transferência de tecnologia, McGee e Prusak (1994) afirmam que a economia baseada em informação torna-a cada vez mais a base para a competição e que os executivos devem identificar claramente o papel que a informação irá desempenhar na estratégia competitiva de sua empresa. Eles consideram a informação como um ativo que precisa ser administrado, assim como outros ativos, capital, propriedades, bens materiais, recursos humanos. Porter (1991) diz que a informação desempenha um grande papel no processo de inovação e melhoramento - tanto a informação não disponível ao concorrente, quanto aquela que o concorrente não procura. Frota (1994) completa a idéia, dizendo que "àquele que detém o conhecimento ou as fontes de informação é facultado o direito de julgar". Fuld (1988) indica diretrizes para uma monitoração da inteligência competitiva nas empresas. Encontramo-nos, hoje, na era da hegemonia cogniscitiva.

O profissional especialista em informação industrial/empresarial deve dominar diferentes áreas do conhecimento, assim como qualquer profissional liberal do novo século. Ele deve conhecer o setor industrial em que atua, as tendências econômicas e mercadológicas de seu país e regiões do mundo vinculadas ao setor industrial em que atua. Conhecimentos gerais são necessários, leitura diária de jornais, conhecimento de psicologia e comunicação para relacionar-se com seus pares, clientes e fornecedores. Um bom conhecimento de português, de inglês e de informática tornam-se hoje sinônimos de alfabetização, para o desempenho eficiente de qualquer profissional. Montalli (1994) discute a questão da capacitação de profissionais de informação, ressaltando a importância de se criarem cursos por região ou estado. Em um país de dimensões continentais e características diversificadas, caberia uma resposta local à demanda por capacitação de pessoal em informação tecnológica-empresarial.

\section{TABELA 1}

\section{Universo da pesquisa: número de unidades de informação para as quais o questionário foi enviado}

- Rede de Núcleos de Informação Tecnológica do PADCT*

- Sistema de informação Sebrae**

- Sistema de Informação CNI*

TOTAL

* Fonte: Guia de Informação Design. São Paulo: Fiesp/Detec, 1991.

** Lista de endereços dos balcões Sebrae de todo o Brasil, gentilmente cedido por Dalila Zago.

\section{TABELA 2}

Sexo dos profissionais de informação tecnológica/empresarial atuando nos sistemas públicos de informação

\begin{tabular}{lrr}
\hline Masculino & 152 & $55,9 \%$ \\
Feminino & 120 & $44,1 \%$ \\
TOTAL & 272 & $100,0 \%$
\end{tabular}

\section{TABELA 3}

\section{Escolaridade}

\begin{tabular}{lrr}
\hline Profissionais de informação & № & $\%$ \\
\hline com apenas 2º grau completo & 39 & 14,3 \\
com graduação completa & 149 & 54,7 \\
com graduação e cursos de especialização completos & 81 & 28,7 \\
com mestrado concluído & 1 & 0,3 \\
com doutoramento concluído & 2 & 0,7 \\
TOTAL & 272 & 100,0 \\
\hline
\end{tabular}

O resultado da pesquisa da CNI/Senai indica os principais produtos e serviços de informação que melhor atendem às necessidades de micro, pequena, média e grande empresa no Brasil.

Com o propósito de contribuir para essa discussão, durante o segundo semestre de 1994 e o primeiro de 1995, elaborou-se um questionário enviado à Rede de Núcleos de Informação Tecnológica do PADCT, sistema de informação Sebrae, e ao da CNI-Campi's, para investigar, no Brasil, os seguintes aspectos do perfil do profissional atuante nas redes públicas de informação para indústria/empresa: sexo, escolaridade em nível de graduação e pósgraduação e formato de oferta de cursos preferidos de especialização e de atualização (tabelas 1 e 2). Outro artigo a ser publicado apresenta os resultados referentes aos tipos de atividades exercidas por nível de qualificação e por sistema de informação.
O número de respostas recebidas foi de 272 questionários, perfazendo $69,2 \%$ do universo investigado. Podese considerar relevante a amostra investigada. Entretanto, em face da diferença no número de unidades de informação de cada sistema, sugere-se que doravante as investigações sejam separadas por sistemas de informação.

Apesar de a maioria ainda ser masculina, observa-se que, neste ambiente, a participação feminina é grande, inexistindo desequilíbrios neste aspecto.

Complementando estes dados (ver tabela 3), acrescenta-se que, entre os 39 profissionais com segundo grau completo, $18(46,1 \%$ dos 39$)$ ou $6,6 \%$ dos 272 encontram-se com graduação em andamento. Entre os 149 profissionais com segundo grau e graduação completas, 11 (7,3\% de 149$)$ ou $4 \%$ de 272 encontram-se cursando especialização. Entre os 81 com graduação e especialização completa, 2 deles $2,4 \%$ ou $0,7 \%$ do total de 272 profissionais de informação encontram-se com o mestrado em andamento. Dados de 1994/95. 


\section{ANÁLISE DOS DADOS}

Os resultados indicam que às vésperas do século XXI o sexo masculino ainda domina o mercado de trabalho na área, em detrimento do feminino, porém de forma equilibrada.

Com referência à escolaridade, observa-se que $100 \%$ dos profissionais de informação atuantes nos sistemas públicos de informação para empresas/ indústrias têm segundo grau completo e que apenas $54,7 \%$ têm graduação concluída. Trata-se de um índice baixo, se considerarmos as características impostas pelo novo paradigma aos profissionais de hoje e principalmente se concordarmos com a preposição de que esse profissional deve inicialmente dominar o conhecimento do setor industrial/empresarial em que se situa.

Os quase $30 \%$ com especialização concluída indicam, por um lado, o amplo trabalho a ser realizado pelas escolas responsáveis pela capacitação desses profissionais, por outro lado, a necessidade de maior ênfase no planejamento da capacitação de recursos humanos por parte dos três sistemas investigados.

Apresenta-se insignificante o resultado no que se refere aos cursos de mestrado. Questiona-se então como esses sistemas de informação tratam a questão das lideranças na área. Que papel eles desempenham, dentro e fora de seus sistemas? Que visão macro possuem das questões referentes aos sitemas a que pertencem? Que soluções aos problemas da área de informação para empresa/indústria no país são capazes de sugerir e/ou implementar? Doutores também fazem-se necessários, nessa área, para ocupar os cargos de maior responsabilidade e destaque, para contribuir com o encaminhamento das questões da área, em nível político de âmbito nacional, e para representar a área em fóruns/reuniões no país e no exterior. Porém, apenas $0,73 \%$ do total de respondentes têm esta titulação - comumente requerida para participação nos debates nacionais das questões afeitas à ciência e tecnologia.
GRÁFICO 1

Sexo dos profissionais

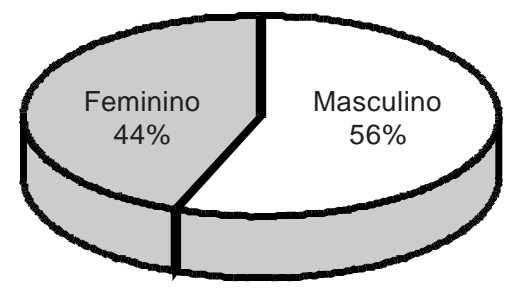

GRÁFICO 2

\section{Escolaridade}

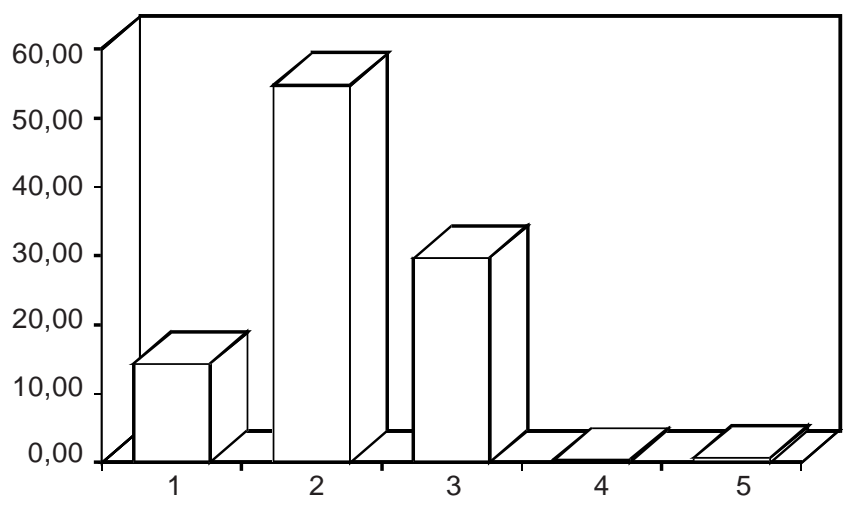

Em uma situação condizente ao que se espera da era do conhecimento, qualquer chefe de seção/departamento de um sistema de informação deveria ter no mínimo o nível de mestrado e os coordenadores/diretores dos sistemas deveriam ser doutores em alguma área relacionada ao setor empresarial/industrial em que atua, ou em informação.

Em face da insignificante percentagem de mestres e doutores identificados nos três sistemas públicos de informação para indústria/empresa, investigou-se a sondagem das atividades exercidas pelo menos por profissionais com essas qualificações e observou-se que serviços de informação com maior componente de valor agregado poderiam ter sido mencionados nas atividades executadas pelos mestres, como, por exemplo, estudos de viabilidade industrial, em detrimento de alguns deles que poderiam ser executados por outro tipo de profissional menos qualificado, tais como alimentação de bases de dados, que demanda tempo, e não requer tanto qualificação. Observa-se, entre os doutores, a responsabilidade pelo papel gerencial, porém ainda envolvidos com prestação de serviços técnicos. Os resultados da investigação indicam que os doutorados foram realizados em ciência da comunicação e em organização e método. Esses doutores fizeram mestrado em ciência da computação e em organização e método - indicando uma capacitação bastante linear. As graduações, entretanto, foram cursadas em biblioteconomia e em administração de empresas. Esses profissionais pertencem à rede de Núcleos de Informação Tecnológica do PADCT Região Sul e Sistema Sebrae de Informação, Região Sudeste, Estado de São Paulo. Dentre as atividades que executam, destacam-se planejamento e gerência de sistemas de informação tecnológica, análise da informação científica e tecnológica, serviço de resposta técnica, gerenciamento de recursos humanos, consultoria empresarial, gestão financeira do sistema de informação.

Em nível de mestrado, concluído apenas por um respondente e em andamento por outros dois, as áreas cursadas são projeto de máquinas, automação industrial e planejamento e gestão de sistemas de informação. As graduações destes profissionais foram cursa- 
das em engenharia, com especialização em segurança do trabalho, em mecânica, com especialização em mecatrônica, bem como em biblioteconomia, sem especialização. Estes profissionais atuam nos Núcleos de Informação Tecnológica do PADCT das regiões Sul e Sudeste e no Sebrae do DF. Dentre as atividades que executam, destacam-se as seguintes: diagnósticos industriais; sondagens tecnológica de empresas e de setores industriais; estudos de nível tecnológico de produtos industriais; transferência de tecnologia; propriedade industrial; serviços de extensão tecnológica; estudos sobre o desenvolvimento tecnológico no Brasil (palestras); qualidade (palestras); elaboração de vocabulário controlado; elaboração de relatórios técnicos; alimentação de base de dados na área de patentes em âmbito internacional.

Entre os 81 respondentes que cursaram especialização, (29,7\% de 272), 41 deles $(50,6 \%$ de 81$)$ procuraram, na área de administração de empresas, essa pós-graduação. Outros 15 (18,5\% de 81), na área de informação. O restante em várias outras áreas do conhecimento. Diante deste resultado, pergunta-se onde se encontram trabalhando os aproximadamente 130 profissionais/especialistas em informação tecnológica oriundos dos quatro cursos oferecidos pela Universidade Federal de Santa Catarina e dos três cursos oferecidos pela Universidade Federal de Minas Gerais? Estariam esses profissionais atuando fora dos sistemas públicos de informação? Que impacto os egressos destes cursos de especialização estariam causando nos sistemas públicos de informação? Destes respondentes dos questionários, 60 pertencem ao quadro do Sebrae, 12 à rede de Núcleos de Informação Tecnológica do PADCT e outros 12 ao quadro do sistema de informação CNICampi's. Alguns deles trabalham em dois empregos, tais como na rede de núcleos e sistema Sebrae, da mesma cidade.

São as seguintes as áreas de graduação preferidas pelos respondentes que não cursaram pós-graduação 149 profissionais: 57 deles ou 38,2\% formaram-se em administração de empresas e 32 deles ou 21,4\% em economia; apenas 12 deles ou $8 \%$ optaram por

\section{TABELA 4}

\section{Áreas de graduação}

\begin{tabular}{lrr}
\hline Administração & 57 & $38,2 \%$ \\
Economia & 32 & $21,4 \%$ \\
Biblioteconomia & 12 & $8,0 \%$ \\
Engenharias & 11 & $7,3 \%$ \\
Ciências humanas & 24 & $16,1 \%$ \\
Contabilidade & 17 & $11,4 \%$ \\
Ciências sociais e médicas & 4 & $2,6 \%$ \\
TOTAL & 149 & $100,0 \%$ \\
\hline
\end{tabular}

\section{TABELA 5}

\section{Formatos preferidos para curso de especialização}

Durante um mês, com intervalos de três meses, seqüencialmente

Durante três meses seguidos

Durante o período noturno, ao longo de um ano letivo

Outros

TOTAL

$\begin{array}{rr}132 & 48,5 \% \\ 55 & 20,2 \% \\ 31 & 11,3 \% \\ 54 & 19,8 \% \\ 272 & 100,0 \%\end{array}$

biblioteconomia e 11 ou 7,3\% engenharia. As outras áreas do conhecimento preferidas foram ciências humanas, com destaque para direito e letras; contabilidade apresenta-se com um índice significativo e, em menor proporção, ciências sociais e médicas. Ver tabela 4.

Se a expectativa era ter maior contingente de profissionais formados nas áreas das engenharias e da biblioteconomia, a investigação evidencia que, ao contrário, administradores de empresas, economistas e contadores, mais do que engenheiros e bibliotecários, interessam-se em trabalhar com informação para empresas/indústrias, talvez pelo fato de a maioria dos respondentes pertencer ao Sebrae. Esses 149 profissionais poderiam ser considerados condidatos potenciais aos programas de especialização e mestrado na área de informação tecnológica empresarial.

Quanto ao formato preferido para os cursos de especialização de 360 horas, os resultados apontam para uma preferência de $48,5 \%$ do formato um mês de curso, com intervalos de três meses e outro mês de curso, sucessivamente até o final de curso. A tabela 5 ilustra $o$ assunto.
O formato preferido apresenta vantagens quando os alunos residem nas proximidades da escola, pois facilita rapidez no acesso à escola e diminui os custos do transporte. O ponto frágil neste caso diz respeito aos alunos que moram em locais distantes da escola, casos em que o custo dos transportes poderia tornar esse formato inviável.

Dentre suas principais vantagens, destacam-se a interação entre ensino/aplicação prática - o aluno traz para a escola questões vivenciadas durante o período em que retorna ao trabalho por três meses, portanto a escola passa a colaborar diretamente na solução das questões diárias que se apresentam no ambiente de trabalho dos alunos.

A segunda preferência de $20,2 \%$ dos respondentes permite que o curso seja oferecido durante três meses seguidos e adequa-se melhor às necessidades dos programas criados para atender a alunos de outras localidades. 
Com respeito aos cursos de curta duração (60/80 horas) - tabela 6 -, a maioria $62,5 \%$ dos respondentes prefere que os mesmos sejam oferecidos durante duas semanas seguidas, no máximo, e em regime de tempo integral. Apenas $25 \%$ dos respondentes optaram pelos cursos de final de semana. Nos casos em que os alunos originam-se de empresas privadas, torna-se provável que esta segunda opção seja a única possível, apesar do desgaste com que o aluno chega ao curso, nos finais de semana. Sugere-se, neste caso, a utilização de técnicas selecionadas de ensino que tornam o processo ensinoaprendizagem mais agradável, tais como discussões, estudos em grupos e outras.

\section{CONCLUSÃO}

A presente pesquisa investigou o perfil dos profissionais de informação tecnológica empresarial em alguns aspectos e conclui que, nos sistemas públicos de informação, há predominância masculina em detrimento da feminina, entretanto sem desequilíbrios exacerbados; a escolaridade apresentou índices de $100 \%$ referentes ao segundo grau completo e $85,4 \%$ quanto ao terceiro grau, curso superior; apresenta-se baixa quanto ao nível de pós-graduação, evidenciando a necessidade de maiores investimentos em capacitação de recursos humanos por parte dos próprios sistemas públicos de informação para indústria/empresa e por parte das políticas de informação, de ciência e tecnologia e industrial. Um total de $29,7 \%$ dos respondentes cursaram especialização, entretanto torna-se insignificante a porcentagem de mestres e doutores na área, respectivamente 0,3\% e 0,7\%. Estes números indicam uma oportunidade de negócios para as escolas responsáveis pela capacitação de profissionais de informação para indústria/ empresa. Existe uma demanda potencial por programas de mestrado e doutorado e outra ainda ampla para cursos de especialização - há de se criar ao menos um programa de especialização por região e um por estado, nas regiões Sul e Sudeste (Montalli, 1994). No momento, apenas a Universidade Federal de Minas Gerais oferece especialização, mestrado e o doutorado em implementação, nessa área.

\section{TABELA 6}

Formato preferido para cursos de curta duração - 60/80h

Durante duas semanas, em período integral

Durante um mês, às sextas e sábados, em período integral

Outros formatos

$62,5 \%$

TOTAL

\section{GRÁFICO 3 \\ Áreas de graduação}

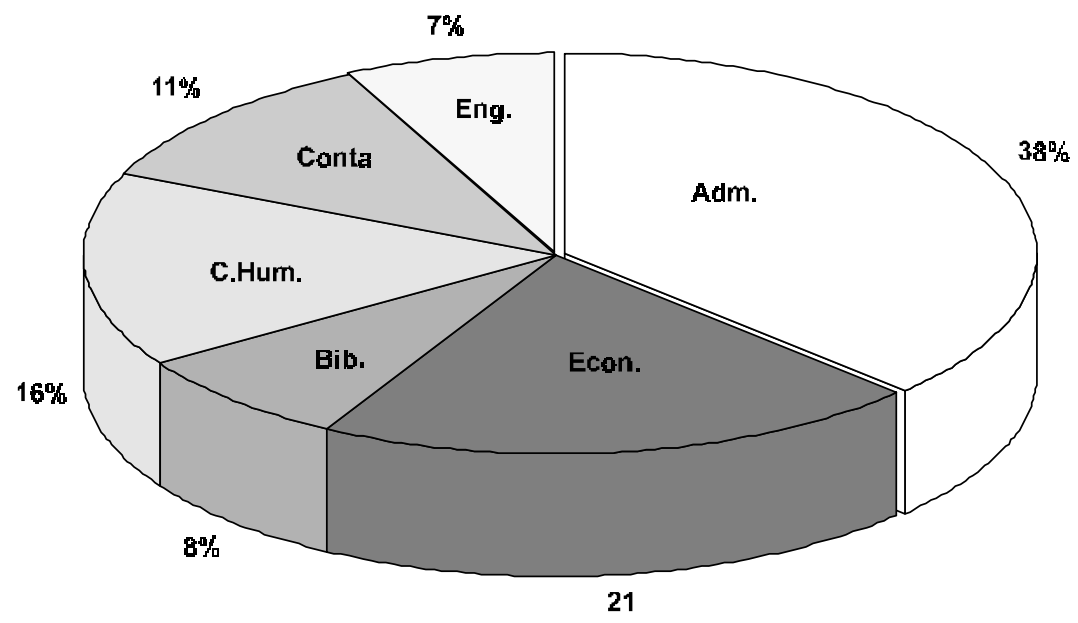

\section{GRÁFICO 4}

Formatos preferidos para cursos de especialização

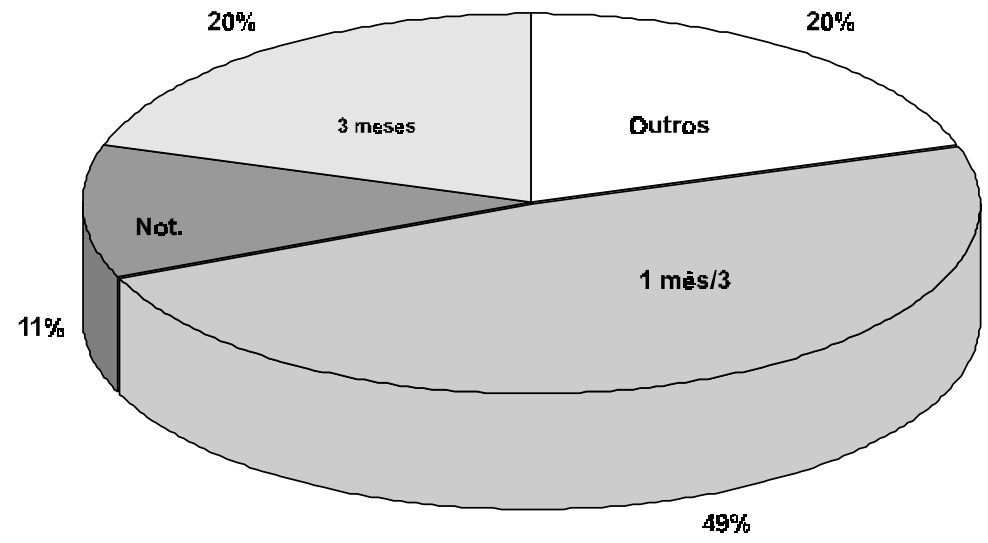

\section{GRÁFICO 5}

\section{Formato preferido/curta duração}

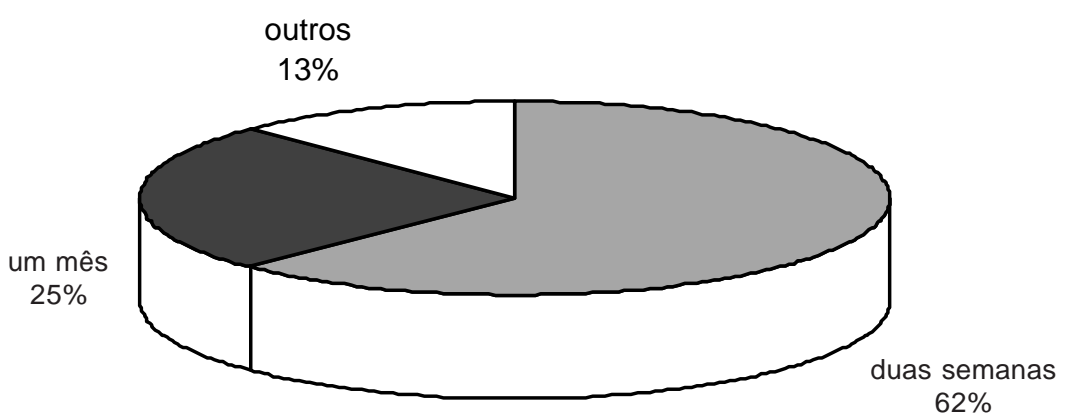


Sugerem-se maiores investimentos por parte dos dirigentes dos sistemas públicos de informação para empresa/indústria, quanto ao planejamento da capacitação de recursos humanos, aos que elaboram as políticas públicas, investimentos específicos para a área. Aos pesquisadores, investigações sobre o impacto dos egressos dos cursos de especialização oferecidos pela Universidade Federal de Santa Catarina (4) e Minas Gerais (3) e investigações comparando o nível de qualificação dos profissionais com os tipos de serviços prestados e a satisfação dos usuários. Sugere-se que as pesquisas sejam realizadas por sistemas de informação, em face das características dos usuários atendidos e serviços prestados.

\section{Profile of the technological and entrepreneurial information professional}

\begin{abstract}
This paper investigates sex, level of education and the prefered way to offer programs of graduation, among the three main systems of information for business/industry in Brazil: PADCT, Sebrae and CNI. It concludes that there is a minor majority of male, that more than a half of them have finished the undergraduation level - Management and Economics being the original areas - however it concludes that there are very short number of professionals with M.Sc. and Ph.D. degrees. It also concludes that they prefer to be trained in courses of 2 months intervals between each one month of class. It makes suggestions on trainings and research for those dealing with these type of information professionals qualification.
\end{abstract}

\section{Keywords}

Information professionals qualification; Information globalization; Industrial/ entrepreneurial information; Prefominance of masculine sex in tecnological information; Sebrae information professionals.
Finalmente, além da discussão sobre os conteúdos que deveriam compor os programas nessa área, outra se impõe: em que escolas esses profissionais de informação deveriam ser formados? Faz-se necessário lembrar que não só existe demanda potencial para a capacitação de profissionais de informação tecnológica/industrial para atuar nos sistemas públicos de informação, mas também para atuar com empresas privadas de informação para atender às médias e grandes empresas. Essa questão merece maiores reflexões e estudos mais aprofundados.

Cursos de pós-graduação localizados em escolas de ciência da informação, em departamentos de engenharia e em escolas de administração de empresas parecem ter vocação inata para desempenhar tal tarefa. As mudanças características do atual paradigma requerem flexibilidade dos coordenadores dos cursos e capacidade de resposta rápida às demandas identificadas e oportunidades de negócios delas decorrentes.

\section{REFERÊNCIAS BIBLIOGRÁFICAS}

1. DEMANDA por informação tecnológica pelo setor produtivo: pesquisa, Rio de Janeiro, Confederação Nacional da Indústria, Serviço Nacional de Aprendizagem Industrial/CIET, 1996.

2. FAULKNER, Wendy. Conceptualizing knowledge used in innovation: a second look at the science-technology distinction and industrial innovation. Science, Technology and Human Value, vol.19, n.4, p.425458, 1994.

3. FROTA, Maurício Nogueira; FROTA, Maria Helena de Arantes. Acesso à informação: estratégia para a competitividade; metodologia para recenseamento e bases conceituais de uma rede nacional de informação em serviços tecnológicos. Brasília, CNPq/IBICT, FBB, 1994.

4. FULD, Leonard M. Monitoring the competition; find out what's really going on over there. New York, John Wiley, 1988.

5. GIBBONS, M. et al. The new production of knowledge: the dynamics of science and research in contemporary societies. London, SAGE Publ., 1994.

6. McGEE, James; PRUSAK, Laurence. Gerenciamento estratégico da informação; aumente a competitividade e a eficiência de sua empresa utilizando a informação como uma ferramenta estratégica. RJ, Campus, 1994

7. MONTALLI, Katia M. Lemos. Informação em Ciência e Tecnologia: capacitação de recursos humanos. TECBAHIA, vol.9, n.12, p.7-10, 1994

8. PORTER, Michael E. National Competitive advantage. in: PORTER, M.E. On Competition and Strategy. Boston, Harvard Business Review Paper back, 1991.
Katia Maria Lemos Montalli

Professora adjunta da UFSCAR - DCI / Coord. GT de Informação Tecnológica da ANCIB. 